\title{
A Call for Curriculum and Faculty Developers to Attend to Ambitious Teaching in Experiential Curriculum
}

\author{
Randi Nevins Stanulis ${ }^{1}$ (i) - Amy R. Guenther ${ }^{1}$ \\ Accepted: 6 November 2020 / Published online: 25 November 2020 \\ (C) International Association of Medical Science Educators 2020
}

\begin{abstract}
To realize the goals of an experiential curriculum, medical educators need support to enact a different kind of teaching: ambitious teaching. Ambitious teaching promotes curricular aims and fosters responsive, interactive environments to elicit student thinking and facilitate student-to-student discussion of clinical concepts and reasoning. The purpose of this article is to provide a framework for ambitious teaching that can be used to meet the complex challenges of experiential learning. Specifically, we describe the ways in which medical education curriculum and faculty developers can support ambitious teaching and, ultimately, enhance curricular outcomes.
\end{abstract}

Keywords Medical education - Teacher development - Experiential curriculum - Learning to teach · Faculty development . Curriculum development

Increasingly, medical schools are adopting experiential curriculum to help students develop essential competencies in problem solving, integrating knowledge, collaborative teamwork, and clinical reasoning [1]. Experiential curriculum requires a shift away from traditional transmission models of teaching to a more challenging form of teaching [2]. To realize the goals of an experiential curriculum, medical educators need support to enact a different, more robust kind of teaching known as ambitious teaching. Thomas et al. [3] argue a successful curriculum is one that supports faculty in meeting contemporary demands of new curriculum. The purpose of this article is to outline a framework of ambitious teaching and suggest ways ambitious teaching can be used to meet the complex challenges of experiential learning. Specifically, we describe the ways in which both curriculum and faculty developers can support medical educators in ambitious teaching from the

Randi Nevins Stanulis

randis@msu.edu

1 Office of Medical Education Research and Development, Michigan State University College of Human Medicine, 965 Wilson Road, Room A202B, East Lansing, MI 48824, USA beginning of curriculum design through enactment and revision to meet and, ultimately, enhance the desired curricular outcomes.

\section{Experiential Learning and Ambitious Teaching}

An experiential curriculum emphasizes experiential learning. Much more than providing medical students with clinical experience, experiential learning entails the transformation of the experience [4] through a process of relearning, resolution of conflicting ideas, adaptation, interactions with one's environment, and creating knowledge [5]. Critical to this process is a knowledgeable other who scaffolds opportunities for students to develop understanding from their unique and collective experience. This knowledgeable other is a teacher who intentionally and skillfully facilitates challenging discussions among students and provides key opportunities for reflection, which is necessary for students to truly learn from the experience [6,7]. Enacting this kind of teaching is what is referred to as ambitious teaching.

Ambitious teaching, originally coined in teacher education, is a purposeful pedagogical approach that fosters responsive, interactive environments to elicit student 
thinking and makes deliberate space for student-tostudent application of clinical concepts and reasoning [8-12]. Ambitious teaching moves beyond the communication of facts [13] to connecting students with the content in the context of authentic experiences [14], providing space for students to puzzle through problems and create explanations together [9]. In enacting ambitious teaching, teachers adapt instruction based on student thinking and develop rigorous standards for participation by all students. Ambitious teaching can meet the goals of contemporary medical education, including helping all students deeply understand concepts and develop skills by deliberately approaching problem-solving through inquiry [15] and strategically promoting independent, lifelong learners. This vision of ambitious teaching has been tested for effectiveness in many classroom contexts with evidence that ambitious teaching impacts student learning [12, 16, 17].

While ambitious teaching has been conceptualized in teacher education literature, it also has promise for medical education curriculum enactment. Notably, ambitious teaching incorporates the six areas of educational evidence that van der Vleuten and Driessen [18] argue should inform medical education practices: elaboration, cooperative learning, feedback, mentoring, engagement, and learning in a social context. Ambitious teaching is a more complex view of teaching and teacher and, thus, involves a fundamental shift in mindset and practice. Faculty developers need to support medical educators in learning to teach in ambitious ways and, equally important, curriculum developers need to plan for ways to help medical educators to teach ambitiously using the experiential curriculum as a tool. The framework provided below can assist them in this work.

\section{A Framework for Ambitious Teaching to Optimize an Experiential Curriculum}

Experiential learning "only becomes effective if it is applied in an appropriate way" [19] p. 161). Thus, it is important to support ambitious teaching that focuses on enhancing curricular methods, congruence, and the teaching/facilitation skills of medical educators in experiential learning. In our framework for ambitious teaching, we apply Feiman-Nemser's [8] central tasks of teaching from the field of teacher education to the context of academic teaching in medical education. Below, we describe specific ways in which medical education curriculum and faculty developers can use this frameworkduring curriculum development, enactment, and revision - to match the ambitious kind of teaching needed to realize the curricular goals of experiential learning.

\section{Creating Conditions that Support Ambitious Teaching}

Before medical educators can enact ambitious teaching, certain conditions are necessary. A primary challenge in moving toward ambitious teaching is being open to and embracing a professional identity as a teacher. Because medical educators often have little training as a teacher, they need explicit opportunities to develop an identity as a teacher. This identity development comes with direct preparation and a feeling of value for teaching. To achieve curriculum coherence, medical educators need to feel they have agency and understand the curriculum and what is expected of them [20]. Thus, the first two central tasks, developing a professional identity and gaining local knowledge, must be attended to early on.

Task \#1: Developing a professional identity as a teacher within ambitious teaching

Teacher agency is an essential part of ambitious teaching. Agency refers to teachers feeling their judgment as professionals is valued and that they have some control over how they teach. Teachers need to feel they are making an active contribution to their work as teachers and to shaping the teaching environment [21]. In asking medical educators to take on ambitious teaching, we likely are asking them to significantly change their approach to teaching and, therefore, their teaching identity. Thus, the ways in which curriculum developers approach this change is vital. van der Vleuten and Driessen contend, "simply telling [medical educators] to change will be the best recipe for disaster. We need to involve them, allow them to experience working in different ways... By doing this well, teachers will also become engaged and this will fuel the change process" [18] (p. 229).

To help medical educators develop an identity in ambitious teaching, curriculum developers need to ensure the purpose of the curriculum is clearly articulated and understood. Input from all faculty who teach should be solicited regularly in order to gain information about curricular understanding. Each medical educator can feel valued when curriculum and faculty developers seek input and actively use this input to support conversations about ways in which curricular goals are being realized. Curriculum and faculty developers can promote medical educator agency by inviting opportunities for shared discussion among medical educators about their ambitious teaching efforts.

Task \#2: Gaining local knowledge of students, curriculum, and medical school context 
Curriculum developers have local knowledge about their vision and desired outcomes for the curriculum. Yet medical educators are often told what they are expected to do without access to decision-making or participating in regular conversations about curricular vision. One way to support medical educators as teachers is to involve them in understanding the curricular vision and collaboratively brainstorm ways for medical educators to use their understanding of the vision as a basis for making adaptations based on their local knowledge and expertise. By co-constructing a shared vision, medical educators who facilitate experiential learning can act in deliberate ways rather than making up their own ideas of what it means to teach in this setting.

Curriculum and faculty developers need to explicitly build understanding together with medical educators about the big picture of the curriculum, discuss together goals for what effective student learning looks like, and have ongoing discussions about ways to prepare for their unique group's experiential learning. In curriculum conversations, medical educators together can discuss questions such as the following: Are the goals and objectives understood by all involved in teaching the curriculum? How useful are various parts of the curriculum perceived to be? Does the curriculum on paper match the real curriculum? [22]. Medical educators need to understand the decision-making process or the "why" behind decision-making in order to feel agency to teach in ambitious ways. As medical educators gain this local view of the context and curriculum, it is possible to feel like a participant in the curriculum rather than merely an implementor. Supporting medical educators in developing a big picture vision of the curriculum and of ambitious teaching also is critical to the other central tasks of ambitious teaching.

\section{Putting Ambitious Teaching into Practice}

In ambitious teaching, the goal is to advance every student's learning. Medical educators need explicit preparation to learn ways in which to respond in the moment during instruction, and to recognize and make connections between students' ideas. These are specialized teaching skills that impact learning. However, these are skills medical educators do not naturally possess. To achieve the goal of advancing student learning, the teacher needs to know students as individual learners; pose questions and make connections between and among student comments; set up, adapt, and debrief interactive learning tasks; integrate clinical experience, model clinical reasoning; and make decisions ahead of time and in the moment about where and how to spend time in order to reach the most crucial learning objectives. The next four central tasks provide insight into enacting these ambitious teaching practices.
Task \#3: Designing responsive curriculum and instruction

Facilitating experiential, interactive learning is a complex undertaking that requires the ability to make informed decisions in the moment much like clinicians do with patients. This ambitious teaching is responsive to student learning needs in the context of the curriculum. To enact responsive instruction, medical educators need to utilize their knowledge of the content and their students to make decisions about what and how to teach in response to their students' thinking. Attention to student thinking in ambitious teaching requires teachers to elicit students' ideas and then adapt their instruction "in the moment... in order to work on and with students' ideas" [23] (p. 181). Adjusting teaching to learning is a critical component of designing ambitious instruction. In order to adjust teaching in the moment, medical educators need ways to gather data quickly during class, by keeping track to be sure all students have a chance to talk, by noting when a student is regularly confused or interrupted, when the group has misconceptions, or when the pacing is too slow or fast.

Responsive teaching also involves asking questions to help students discover possibilities based on their experience [24]. It ensures students have opportunities to make connections between the content and their experiences and that all students have a chance to share their ideas. This sharing can occur in partners, small groups, or whole group. Medical educators can use question stems that promote reflection, such as the following: In what ways...? Can you think of another way...? What is one important idea from our discussion that helps you...? Curriculum and faculty developers, together with medical educators, can build in examples of a range of questions, ideas for ways of structuring interactions to engage all students, and ways for medical educators to utilize their clinical expertise to foster student learning. In order to be effective in ambitious teaching, medical educators need regular opportunities to share ways they are asking questions, providing feedback, creating an open and exciting learning environment, and promoting independent learning [22].

Task \#4: Enacting a teaching repertoire in purposeful ways

With a clear vision of curricular goals for experiential learning, medical educators can develop the agency to take up aspects of ambitious teaching, including being purposeful in their planning for teaching and implementation decisions. Being purposeful in decision-making that aligns with the curriculum is essential, as this clarity is what enables teachers to scaffold student learning 
effectively [25]. Medical educators need support both in building a repertoire of instructional approaches that align with experiential learning and in developing the ability to be purposeful in their instruction-to access particular approaches at strategic moments to promote curricular goals and optimize student learning.

Supporting ambitious teaching involves helping medical educators use authentic tasks that require students to apply knowledge at the same time necessary science content is being reinforced. A part of purposeful teaching then relies on the teacher understanding and setting up the defined curricular tasks. Curriculum and faculty developers can help by working together with medical educators to identify the few big learning goals that must be met during a teaching session and provide a variety of activities for medical educators to choose from based on group learning needs that maintain key learning goals. In ambitious teaching, curriculum is organized by an authentic task referred to as anchoring event, which involves motivating students to try to explain what might be going on. A patient case can be part of an anchoring event. This anchoring event is accompanied by a driving question, such as "What makes wounds heal in different ways? or "Why is asthma so prevalent in poor urban communities?" [12] (p. 31). With an anchoring event and questions that drive instruction, the medical educator can purposefully provide instruction that keeps students focused on engaging in high level thinking toward learning goals.

\section{Task \#5: Creating a classroom learning community}

Enacting an experiential curriculum in ambitious ways requires creating a respectful and productive learning community where everyone feels their voices are valued and where attention to equity of talk is a part of the curriculum design. As Lampert, Boerst, and Graziani note:

Ambitious teachers need to lead discussions in which students learn from talking about ideas and enable students to engage productively in collaborative investigation with partners they might not choose as friends. This means making the classroom into a social environment in which all students are willing and able to perform in front of others in domains where they are only partially competent (p.1367) [14].

Curriculum developers need to pay attention to group dynamics while designing curriculum, with clear student interaction structures (e.g., Think-Pair-Share, purposeful partnering to be sure introverts are heard, teams, rotating students as facilitators) planned for each learning session.
While creating a learning community, curriculum and faculty developers and medical educators together can discuss in what ways they are encouraging learners to actively participate, or whether learners are able to hide what they don't know [22]. In ambitious teaching, interpreting student nonverbal and verbal behavior, and communicating with students in ways that engage rather than isolate, is essential to productive learning [26].

Task \#6: Learning in and from teaching practice

It is important to recognize much of what needs to be learned about teaching can only be done while teaching [8]. Yet merely gaining experience teaching does not mean medical educators are prepared to learn from this experience. Medical educators need deliberate support to adapt while in the moment of teaching and to reflect on teaching. In order to develop as ambitious teachers, teaching practice should be seen as a site of inquiry where data are collected, analyzed, and discussed together with other medical educators and curriculum and faculty developers with an eye toward continual growth and improvement. The social work of analyzing data from teaching and learning [27] includes medical educators learning ways to gather evidence about student engagement and understanding and using this data to co-plan and rehearse ideas with other medical educators. Curriculum and faculty developers should be in the room to learn from clinicians' experiences and ideas, in order to provide feedback and learn from their ideas and adjust the curriculum as needed. Curriculum and faculty developers can also support medical educators in this work by regularly co-planning parts of curriculum in groups with medical educators rather than separate from medical educators and conducting rehearsals with medical educators and curriculum developers. They can also have medical educators set teaching improvement goals and share their progress through a shared discussion of data from teaching, so all are learning from teaching.

\section{Cultivating Ambitious Teaching in Curriculum Design and Enactment}

Curriculum and faculty developers need to play an explicit and active role in cultivating ambitious teaching by medical educators. These principles apply to small- and large-group settings in any size medical school. Here, we provide concrete, practical ways for curriculum and faculty developers to realize the goals of ambitious teaching through the central tasks of teaching [8]: 
Developing a professional ident
as a teacher
Gaining local knowledge of
students, curriculum, and medical school context

Designing responsive curriculum and instruction

Enacting a teaching repertoire in purposeful ways

Creating a classroom learning community

Learning in and from teaching practice (continued)

$$
\begin{aligned}
& \text { - Have medical educators regularly } \\
& \text { set and articulate progress with } \\
& \text { teaching improvement goals }
\end{aligned}
$$

\section{Next Steps}

Many medical schools now emphasize experiential learning through integration of classroom and clinical-based experiences where knowledge creation, through reflection and analysis of experiences, is the goal [4]. However, the potential of these curricular efforts cannot be realized through a traditional, transmission model of teaching. A different kind of teaching - ambitious teaching - is needed. Whether in smallor large-group instructional settings, ambitious teaching promotes curricular aims through purposefully fostering responsive, interactive environments to elicit student thinking and facilitate student-to-student discussion of clinical concepts and reasoning. Ambitious teaching requires a distinct view of teaching, an understanding of the curriculum and complexity of experiential learning, a specialized skill set, and, consequently, curriculum and faculty developers' explicit attention.

Ambitious teaching is possible in remote learning sessions such as precipitated by the move to online classes during COVID-19. Online interactive technologies can be used to reach the same instructional goals. Similar to any instructional strategy, it is essential to consider the specific purpose for different technology use and how that purpose matches ambitious teaching. For example, Poll Everywhere is a student response system that can be used to elicit interaction from every student in order to monitor student understanding. Pear Deck, an interactive way to add free response, multiple choice, and drawing, allows an instructor to elicit voice and equity in participation. Such classroom response systems can promote learning when coupled with appropriate pedagogical methodologies [28].

Regardless of whether instruction is in-person or remote, curriculum and faculty developers need to involve medical educators in continuous discussions about curriculum development, enactment, and revision in order to support effectiveness in ambitious teaching. Based upon our experiences, we believe the framework presented here can assist curriculum and faculty developers in this work and offer some practical next steps. To support medical educators to enact ambitious teaching, curriculum and faculty developers can bring all of their medical educators together to collaboratively create a purpose and vision for teaching in the new curriculum. They also can provide a series of faculty development sessions that emphasize ambitious teaching as unnatural work that needs to be learned [29]. Finally, they can support groups of medical educators to study their development as ambitious teachers across an academic year. These practical actions are ways 
we have put the principles in this framework into action. We invite curriculum and faculty developers to do the same-to use this framework to support ambitious teaching, as medical educators cannot be expected to enact ambitious teaching alone.

\section{References}

1. Association of American Medical Colleges. Policy priorities to improve our nation's health. https://www.aamc.org/advocacy/ 472826/policy-priorities-improve-nations-health.html. Published, November 2016; Accessed Sept 19, 2019.

2. Ward A, Stanulis R. Improving medical education through targeted coaching. Med Sci Educ. 2020.

3. Thomas P, Kern D, Hughes M, Chen B. Curriculum development for medical education (Third Edition). Baltimore: John Hopkins University Press; 2016.

4. Kolb DA. Experiential learning: Experience as the source of learning and development. Englewood Cliffs: Prentice-Hall; 1984.

5. Kolb AY, Kolb DA. Experiential learning theory: A dynamic, holistic approach to management learning, education and development. The SAGE Handbook of Management Learning, Education and Development. Thousand Oaks: SAGE Publications; 2009.

6. Dewey J. Experience \& education. New York: Free Press; 1938.

7. Ende J, Atkins E. Conceptualizing curriculum for graduate medical education. Acad Med. 1992;67:528-34.

8. Feiman-Nemser S. From preparation to practice: Designing a continuum to strengthen and sustain teaching. Teach Coll Rec. 2001;103:1013-55.

9. Haverly C, Calabrese Barton A, Schwarz C. Making space: How novice teachers create opportunities for equitable sense-making in elementary science. J Teach Educ. 2018;71:63-79.

10. Lampert M, Graziani F. Instructional activities as a tool for teachers' and teacher educators' learning. Elem Sch J. 2009;109: 491-509.

11. Newmann F \& Associates. Authentic achievement: Restructuring schools for intellectual quality. San Francisco: Jossey-Bass; 1996.

12. Windschitl M, Thompson J, Braaten M. Ambitious science teaching. Cambridge: Harvard Education Press; 2018.

13. Peurach D. In pursuit of ambitious instruction: Leading for deeper learning. https://blogs.edweek.org/edweek/edtechresearcher/2017/ 01/in pursuit of ambitious instruction leading for deeper learning.html?print $=1$. Published, January 2017 ; Accessed Dec 11, 2019.
14. Lampert M, Boerst TA, Graziani F. Organizational resources in the service of school-wide ambitious teaching practice. Teach Coll Rec. 2011;113:1361-400.

15. Irby DM, Cooke M, O'Brien BC. Call for reform of medical education by the Carnegie Foundation for the Advancement of Teaching: 1910 and 2010. Acad Med. 2010;85:220-7.

16. Stanulis RN, Little S, Wibbens E. Intensive mentoring that contributes to change in beginning elementary teachers' learning to lead classroom discussions. Teach Teach Educ. 2012;28:32-43.

17. Stroupe D. Beginning teachers' use of resources to enact and learn from ambitious instruction. Cogn Instr. 2016;34:51-77.

18. van der Vleuten CPM, Driessen EW. What would happen to education if we take education evidence seriously? Perspect Med Educ. 2014;3:222-32.

19. Yardley S, Teunissen PW, Dornan T. Experiential learning: Transforming theory into practice. Med Teach. 2012;34:161-4.

20. Harden R, Laidlaw J. Essential skills for a medical teacher. London: Elsevier Publishers; 2017.

21. Biesta G, Priestley M, Robinson S. The role of beliefs in teacher agency. Teach Teach. 2015;21:624-40.

22. Kern D, Thomas P, Howard D, Bass E. Curriculum development for medical education. Baltimore: John Hopkins University Press; 1998. p. 1998.

23. Stroupe D, Windschitl M. Supporting ambitious instruction by beginning teachers with specialized tools and practices. Newly Hired Teachers of Science: A Better Beginning. The Netherlands: Sense Publishers; 2015.

24. Maudsley G, Strivens J. Promoting professional knowledge, experiential learning and critical thinking for medical students. Med Educ. 2000;34:535-44.

25. Seidel T, Rimmele R, Prenzel M. Clarity and coherence of lesson goals as a scaffold for student learning. Learn Instr. 2005;15:539 56.

26. Bain R. Rounding up unusual suspects: Facing the authority hidden in the history classroom. Teach Coll Rec. 2006;108:2080-114.

27. Crues RL, Crues SR, Steinert Y. Medicine as a community or practice: Implications for Medical Education. Acad Med. 2017;93:185-91. https://doi.org/10.1097/ACM. 0000000000001826.

28. Fies C, Marshall J. Classroom response systems: A review of the literature. J Sci Ed Tech. 2006;15:101-9.

29. Ball DL, Forzani F. The work of teaching and the challenge for teacher education. J Teach Ed. 2009;60:497-511.

Publisher's Note Springer Nature remains neutral with regard to jurisdictional claims in published maps and institutional affiliations. 